Muiraquitã, PPGLI-UFAC, v.2, n.1, Ju1/Dez, 2013

\title{
MODULAÇÕES CONCEITUAIS DOS MULTIVERSOS EM LITERATURA: OS LABIRINTOS HIPERTEXTUAIS
}

\author{
João Carlos de Souza Ribeiro \\ Universidade Federal do Acre - Brasil
}

\section{RESUMO}

Poeticismo e problematização acerca do hipertexto na literatura e seus desdobramentos epistemológicos. Texto, hipertexto, malha textual e complexo tessitural: modulações do texto no universo on line e estruturas dos espaços dimensionais e adimensionais na $w w w$. Variáveis do hipertexto literário e suas modulações no jogo da linguagem em processo de virtualização. Real e virtual congeminando as cadeias semânticas do texto literário. Significação, metassignificação e ressignificação do texto e hipertexto literários, e abertura dos portais da linguagem artística on line. Introdução do conceito de multiversos em literatura e a renovação do pensamento sobre os limites da linguagem artística.

PALAVRAS-CHAVE: Hipertexto. Malha textual. Ressignificação. Multiversos. Poeticismo.

O móvel condutor, que vislumbra o horizonte da Literatura como corpo sem fronteiras é, a priori, uma instância adimensional. Tal assertiva, per si, não define nem tampouco redefine os espaços nos quais estão ancoradas as premissas da Literatura e do fenômeno literário, especificamente no turno da teorização, do criticismo e, também, do poeticismo convergente. No complexo tessitural, onde os corpos literários desmembram-se ou são desmembrados para tornarem-se ilhas flutuantes, autônomas, em universos do dito, do contradito e do não - dito, há conexões múltiplas e infinitas, que, para além, dos estatutos lógicos, revelam as fronteiras do ilimitado.

Se, por um lado, os estudos literários avançaram, significativamente, no que tange à substância, que constitui o tecido artístico e sua natureza distintiva, na realidade objetiva, por outro lado, a Ciência da Literatura não deslindou, desde as senhas aristotélicas e seus desdobramentos filosóficos, a problemática que incide sobre a parábola e 
sua curva modelar no/sobre o texto artístico. Neste seqüenciamento, persiste, ao olhar do investigador, em Literatura, a existência de nuvens espessas, que impedem, sobremaneira, a observação e, por conseguinte, a constatação de tópos, ainda desconhecidos, e, portanto, não - experienciáveis pela letra científica em questão.

A inefabilidade, uma das características da Literatura, a meu ver, tornou-se a cristalização do deus romano Janus, cuja face, encarnando o duplo visceral; o jogo do contrário, no tempo e no espaço, considerava duas realidades antagônicas e paradoxais, que jamais comporiam a unidade, a totalidade: módulo utópico do idealismo humano. Assim, o descompasso vetorial, em que as forças descambam para lados opostos, produz, em Literatura, a natureza da ambigüidade - variável incondicional para que um texto literário seja qualificado como artístico. No entanto, o indeterminismo das formas aparentes e da substância poética, em cadeias metassignificativas, encarcera o cientista da linguagem, que, mais do que a linha turva diante da consideração empreendida, é limitado, aquele, pela ambiência do fenômeno literário, ao promover, em última instância, o desfazimento das bordas e a compreensão em movimento linear, retilíneo e, quiçá, plano. Em Literatura, as paisagens são irregulares, os limites inexistem, as formas são fractais e a linha é tracionada pelo movimento curvilíneo; império preponderante de uma Linguagem de formas expansionais e robustamente circulares.

As reflexões que orbitam o circuito, no qual emerge a verdade literária, refletem, a posteriori, a impossibilidade para determinar segmentos, retas e perpendiculares, que poderiam coadjuvar na tentativa de desvelar a mensagem cifrada no texto literário e seus ângulos, rastreando o possível, no texto considerado artístico. Desse modo, cumpre observar que há pontos, aparentemente desconexos e 
não - coesos, que se interpenetram e se desvinculam ao sabor de marés gravitacionais, cuja força de atuação pode advir de qualquer lado: seja pelo viés daquele que recebe a obra, daquele que a produz, do amálgama que a constitui ou do movimento vertical que o tecido artístico impele. A obra, eminentemente artística, tende a romper limites, barreiras; o tecido literário, essencialmente, um elemento que porta o $\mathrm{mi}$ nisterium, deve, implacavelmente, ser desfeito. Uma vez rota, a malha textual obtém outros contornos; e, assim, descreve o traço sinuoso da curva. É como num oásis de hologramas mortais: o destecimento da teia instaura outros mundos, outras margens.

A configuração do literário, em sua condição fenomenológica, se constrói a partir de um espaço sem dimensão, e promove a expansão de seus limites para desconstruí-los, de forma insidiosa. Este paradoxismo, que caracteriza o objeto estético como corpo suspenso, e em vácuos desmesuráveis, é um dos vestígios inequívocos para vislumbrar a natureza daquilo que se apresenta enquanto elemento artístico bem como para facultar, ao estudioso da Arte, e, no caso em tela, a Literatura, a possibilidade para perceber os abismos textuais, o espaço, aparentemente vazio, que separa a visão crítica do limite que se desfaz alhures, e, fundamentalmente, o redimensionamento dos espaços, que se comportam como entidades ubíquas. O texto literário, desse modo, é um corpo vivo, e, como tal, responde a processos simbióticos peculiares. A leitura, portal de (ultra)passagem para uma realidade transfigurada, conduz o leitor arguto a universos distintos, que coexistem em vagas multilaterais.

A substância poética, ao revelar, no turno das tensões, a verdade literária, aponta o fio continuum e luminoso, que, na desconstrução das bordas do tecido literário, alarga a malha textual, configurando, destarte, a condição hipertextual da/na Literatura. O texto artístico, neste 
sentido, antes de ser plasmado na tela retangular e gélida dos personal computers, é, por excelência, hipertextual. As margens nascem, morrem e se transformam em limites renovados, através da colheita constante, realizada pelo exercício recepcional daquele, para além do ato de ler; radicalizada, indubitavelmente, no advento da compreensão. Compreender, portanto, o texto literário, é conhecer e alcançar o limite, que se torna ilimitado, e que se refaz como teia que se parte e se regenera contínua e eternamente.

Em Literatura, há nódoas em desenlace constante, que produzem outros enlaces, sempre em conjunções infinitas; movimentos que se revigoram, através do quantum poético e da atemporalidade da obra de arte escrita. E tais movimentos estão também presentes no mundo digital. Na tessitura on line, há pontos configurados, que se desconfiguram, intermitentemente, para reconfigurarem-se, balizando e alargando as fronteiras do texto virtual por meio dos links - janelas digitais, que operam a abertura doutro modo de compreensão da realidade, que não se calca mais em modelos constatáveis e equacionáveis pelos grafismos incidentais.

Ora, se a Literatura é a grande anfitriã, que abre os portais, e que, por sua vez, se reconfiguram diante do processo em seu acontecer; em seu devir; i. e., a questão poética, propriamente dita, o universo hipertextual é parte integrante e inalienável deste processo, onde a letra artística é, para a fortuna de homens e divindades, a imagem plasmática, indefinida, estética e não - quantificável, que reelabora o modus operandi, ao desvendar os rumos renovados da escrita literária, no turno científico, no turno disciplinar, e, claro, no turno artístico. Assim, não se pode deliberar sobre as sentenças que tratam do paralelismo a marcar a literatura, quando esta última é revista pelo prisma inconfundível da hipertextualidade. A hipertextualidade é, desse modo, a condição 
de ser da Literatura em seus múltiplos espaços de ressignificação e, portanto, de sua linguagem, que, em fluxo constante, reinventa o mundo sob novos instrumentos; outros canais, que, aparentemente, conduzem o Homem a túneis obscuros, mas que, em verdade, verticalizam a palavra para que o lógos seja reacendido no limite do (im)provável. Tal configuração sugere a imagem terrífica do abismo, sempre necessário, para que ideia ou sentença alguma delimite os níveis circulares da Literatura, que avançam, e, por isso, hipertextualizam-se ao sabor de teias maiores, paralelas, coexistentes e multidiversas.

Entabulada como mídia, a Literatura, ao instrumentalizar-se como rede informacional, não se aparta de sua função primordial, que é a de transfigurar a realidade objetiva em sua radicalidade poética. Antes, a Literatura, operando em níveis lúdicos, resguarda sua verdade incorruptível e infalível e dribla os atores ditos novos, no turno inequívoco da palavra, que se constrói e se desconstrói, revalorando sentenças, renovando pensamentos e metassignificando símbolos: elos que conectam e hiperconectam textos, retroalimentando o vigor do/ no tecido literário. Na condição de malha textual, o texto não cresce, embora o horizonte visionário do estudioso em literatura aponte para este fenômeno. A malha textual invade outros espaços. Lugares não - dimensionáveis pelo pensamento lógico, mas que, paradoxalmente, podem ser segmentados pela virtualidade, que subjaz a letra literária em sua essência poética. A natureza de ser fundante, que é a da Literatura, transforma esta última na senha para adentrar universos não - visíveis por olhos humanos ou câmaras mais do que claras, mas perceptíveis pela letra poética, cuja substância de fundação é a matéria responsável pelo componente virtual, elemento constituinte do tecido literário e ampliado pela malha textual, no processo de desfazimento das fronteiras. 
A Literatura, ao se apresentar como discurso singular no código social, condensa, na linguagem humana, os valores representativos de uma ou de várias realidades para reconfigurá-la a partir da visão única e, também, singular do artista. $\mathrm{O}$ fenômeno que amalgama as realidades, cognoscíveis e ignotas, em conjunção, verticaliza o sentido da linguagem cerrada sobre si mesma para desconstruir a própria essência. A palavra, em sua força concêntrica e aguda, implode os possíveis edifícios, que constroem o pensamento, e produz a onda que derruba as fronteiras do visível no espaço possível do literário. Desse modo, o hipertextual metaboliza o textual e a grafia do que não é / não está atravessa, fenomenologicamente, o turno do que é em sua abrangência circular. Neste jogo aparente do contradito, constatam-se a tensão e a hipertensão na circularidade imanente da própria Literatura, pois o texto, ao navegar em fluxo aberto, crescente e precipitado, não desfaz as variáveis primas, que o tornam objeto estético, mas redimensionam seus limites em sua corporeidade alargada, discorrendo, contínua e descontinuamente, para todos os lados. Destarte, o que é ubíquo tornase universal, a priori, e multiverso, a posteriori.

As possibilidades de compreensão do que é literário, em sua extensão significativa e metassignificativa, sublinham a maestria da Literatura, que não perde seu vigor originário, e que, revalorada, se refaz enquanto discurso temporal no contrafluxo das linguagens concorrentes e operantes na / da realidade objetiva. O mundo visto como teia que se agiganta, englobando as realidades em gradações confluentes e complementares, a meu ver, é um espelho de dimensões colossais, que refletem o módulo complexo e tracional, que é a Literatura, em sua grandeza não - mensurável. Se a questão orbita em torno do Hipertextual e de sua condicionante invariável, a hipertextualidade, o texto literário, na tessitura em progressão aritmética e geométrica, traz, em sua constituição originária, a marca do que é hipertextual ou da hi- 
pertextualidade subjacente àquele. O que pode escapar ao olhar do teórico e/ou do crítico literário é a linha tênue que divisa o abstrato do não - abstrato, no qual estão os pólos determinantes do que é textual e do que é hipertextual. Assim, é meu intento trazer à lume a condição latente do hipertexto, em ordem primária, para, no lance reflexional, mostrar as gradações que fazem do texto o elemento móvel que se transfigura, ao deteriorar as amarras aparentes, deslocando-o de seu porto rígido, e, portanto, desancorando-o, de forma contundente, para que, no movimento corpóreo e na qualidade de tecido vivo, possa, com efeito, navegar, autonomamente, respeitando suas próprias leis; acentos e rubricas, que o caracterizam como componente indispensável para a apreensão do Real, sob o primado da arte escrita.

A substância que opera o duo fundante - fundado, desarraigada do exercício do nomear, que impõe os limites reducionistas da realidade, emerge no Real, ora como clarão, ora como sombra, e revela, de forma crescente, a essência que a constitui: a textualidade. Neste sentido, se o hipertexto explode na metassignificação, ricocheteando sentidos, reconfigurando a teia e aumentando ad infinitum o complexo tessitural, o fenômeno contrário é validado pela condição daquele em seu poder inconteste de síntese. A análise impõe o hipertexto como alargamento do texto para a compreensão doutros sentidos e doutras linguagens em tomos entrelaçados, cruzados e riscados. A síntese determina o reverso do movimento da malha, que, uma vez aumentada, pode recrudescer-se a si mesma para desvelar o núcleo de fundação daquela. Este é o movimento intrínseco do texto, cujo corpo modula as funções de abertura e fechamento para as realidades que existirem; i. e., todos os níveis que, refratados pela Luz, podem ser e/ou estar visíveis para a íris distorcida do Homem como passageiro efêmero e limitado no real absoluto. 
Clarifico, na condição de poeticista, que a Literatura sem a hipertextualidade estaria fadada à ruína como ilha, que é devastada por um cataclismo de grande envergadura. $\mathrm{O}$ que pode parecer um estranhamento para muitos leitores, que, inadvertidamente, não percebem as linhas imaginárias por que passa aquela, é, na verdade, o desvelamento de um exercício mais denso e radical da letra - artística, que verticaliza a sua natureza como tecido, ao redimensionar a própria realidade, através da questão de base ontológica. Ao vislumbrar o literário em sua expressividade, descobre-se, a priori, a imagem refletida no espelho, que, necessariamente, não deve corresponder à realidade da qual aquela originou. Ao contemplar o que está no decurso / discurso do literário, apreende-se, a posteriori, a não - finitude daquele, que, para além de ser uma imagem refletida, é, de forma cabal, uma janela que se abre para vários universos do sem fim. Labirintos oblíquos, em terceira dimensão, fantasmagóricos, mortais, atraentes; e todos, invariavelmente, sem saídas. O que é universo se transforma, ludicamente, em multiversos. E, na eclosão do texto, que se hipertextualiza, várias faces emergem de um nascente enigmático, em que a luz, paradoxalmente, não está a serviço da iluminação, mas, antes da fabulação. Há crepúsculos, curvas descendentes, monstros híbridos, homens voadores e asas derretidas por sóis que crestam verdades, sob a efemeridade de dedos, que, sofregamente, apenas tocam teclas e escorrem sobre dígitos frios, mudos, mas não mitológicos. Na clareira do que é translógico, (grifo meu) o confronto, senão bestial, mas avassalador de realidades que se chocam, brutalmente, como se redesenhasse no imaginário coletivo a caótica cena do Big Bang. O que está em jogo, neste espaço de convergências e divergências, não é, com efeito, o improvável, que poderia ou se tornou probabilidade, mas a verdade mais recôndita, que, provocada, sobressalta diante das tecnologias, ao remodelarem formas, conteúdos, sentidos e objetivos. 
O confronto entre mundos, aparentemente inversos, em verdade, aponta para dois níveis de significação da realidade, que se instaura como viés alternativo para a compreensão doutros patamares daquela. A saber: a disparidade, que se desfaz pelo seu contrário, pois, nos fios da dessemelhança, há elos semelhantes; e a inversão das efígies, em que há um corpo singular; indissociável em sua totalidade. A tentativa de separação do duo que compõe o uno é, indubitavelmente, a desconstituição do que é; a dessubjetivação da palavra como instrumento primo; a dessencialização do corpo textual; a perda das margens do espaço tessitural e o acidente do móvel, que, à deriva, se transforma em um elemento nulo, de contornos indefinidos e sem quaisquer referências, que possam estabelecer elos de representação - links - no universo no qual o texto trafega, em instância primária. Tais assertivas representam a ratificação universal das coisas que são pela completude e pela totalidade que a constituem. Teorias não existem sem práticas e práticas não existem sem teorias. A luz existe somente porque o pano de fundo fora formado pelas densas trevas; a força da rainha no jogo de xadrez seria inócua sem a existência frágil e débil do rei; a vida não existe se não houver a morte, e a morte jamais teria sentido se não existisse a vida - massas diferentes, que dão forma à realidade e que sustentam o espaço ontológico no qual todas as coisas, todos os entes são sem nunca terem sido. Indago: seria isto o Inominável (?)

A classificação genérica de Literatura, que trata da abordagem de tudo que pertence ao ambiente da palavra e da escrita, em suas formas midiáticas diversas, não encontra impeditivos para o fluxo de seu trânsito, nos canais em que o texto, dos mais simples aos mais complexos, constitui-se no instrumento modular de/da informação. Particularizando aquela, no circuito do verbo de fundamentação artística, paradoxalmente, a letra que manifesta a Arte é posta em questão. Suspensa como tomo significativo, portanto, a letra - artística é per- 
cebida como um elemento suscetível à deterioração por não suportar as estruturas, que servem de canais para o exercício da expressão da palavra em seu objetivo pleno. O paradoxo aqui referido está inserido no seu contrário, de ordem absoluta. Aquilo que se apresenta como fluxo constante de dados contínuos e inumeráveis, onde o empilhamento de informações infla as redes midiáticas e produz um atrito contínuo e exacerbado, é, com efeito, o abismo que não é percebido na realidade objetiva. Desse modo, a palavra, um componente essencial, singular e, sobretudo, singelo, em sua origem, torna-se um elemento áspero, aparentemente insensível e, desse modo, uma lâmina cortante, que não abre caminhos, mas, antes, arranha superfícies, cria fossas, trilhas pedregosas, caminhos acidentados e irregulares; um ambiente inóspito para aquele se lança na desventura das provas mais atrozes, que aquela pode submeter. Corrompida, portanto, a palavra, em desgaste visceral, não tem mais a aparência nem tampouco a essência de quando verteu de sua fonte originária. Ainda que o mundo tecnológico jamais reconheça esta abordagem conceitual sobre a origem da palavra, na qualidade de lógos fundador, a leitura poética é a mais crível dentre tantas outras possíveis; é, de forma incondicional e imbatível, o reconhecimento do berço que dá origem ao verbo, seu campo de significação, na realidade, na qual se insere, e, fundamentalmente, na metassignificação - turno de derrubada das fronteiras, do desfazimento fenomenológico dos limites e do alargamento das margens que se constroem e se desconstroem, de forma simultânea e enigmática.

A visão (do) poeticista percebe, em larga escala, a dimensão do fenômeno do texto que se hipertextualiza, tendo localizado, no uso da palavra, a inversão dos processos, que, paradigmaticamente, expurgam a extensão daquela quando a ascensão do hipertexto modula outras configurações e/ou reconfigurações no complexo tessitural, que é, em última análise, a malha textual em franco processo de crescimento, 
nos universos em que navega, com vias a consolidar a sua condição inequívoca de variável atemporal.

Ora, se a palavra interconectada em outros tecidos faculta as possibilidades doutros modos de apreensão da realidade ou das realidades, o índice de infinitude dá um salto quântico na malha textual, que modula espaços lacunares contíguos, promovendo a aparição de instâncias ligadas por links a conferirem, em instância posterior, a superestrutura que o texto adquire. Logo, em se tratando de cadeias binárias, de bites, escalas numerológicas, que, nas incontáveis interfaces, favorecem o intercâmbio de dados, mantendo a conexão da rede, propriamente dita, em ambientes cada vez maiores, o texto, que não é o artístico (texto não-literário), transita, de forma equacionada, passando pelo atrito, que o desconfigura na essência, segundo o ambiente no qual está inserido - a teia virtual -, para dimensionar e superdimensionar todas as cadeias informacionais em curso e não - previsíveis numericamente. É irrefutável a tese, portanto, de que neste nível de programação da linguagem, que desdobra o texto em hipertexto, e em gradações sempre crescentes, o risco do não - finito, que permeia esta esfera, pois o lógos, em sua morfologia, e com sentidos endógenos e exógenos, é rastreado e problematizado por códigos matemáticos. A proporção das variáveis é equalizada pari passu pelas possibilidades da construção de um texto, operado pelo maquinarismo digital, que torna acessível aquilo que não é perceptível aos olhos desnudos; i. e., o mundo virtual em sua ordem de grandeza, que se expande, esfericamente, para abarcar o hipertexto em suas modulações previsíveis e não - previsíveis.

O texto literário, por ser um módulo singular e representativo da Arte, e, também, por conjugar o lógos essencial, em níveis fundadores, e que, por sua vez, não é corroído ou desgastado por força externa 
alguma, torna-se um hospedeiro ímpar no mundo digital. Artístico, por excelência, o texto redefine outro modus operandi daquilo que emerge no Real, atualiza-se em potência máxima e mergulha nas marés gravitacionais e antigravitacionais do universo on line. Neste sentido, o texto artístico, uma tessitura, eminentemente poética, traz em sua constituição as faces inversas e reversas do Real e do Virtual em dinamismo duplo, onde o imanente e o transcendente não desfiguram, no alargamento da malha e na condição de teia textual, o traço virtuoso do que é artístico - da fundação à eclosão; ou da força concêntrica ao expansionismo absoluto daquele, seja na realidade objetiva, seja na realidade virtual. E neste intercurso, ainda, há que se pontuar, de forma explícita, que o texto e o hipertexto literários, respectivamente, não desprezam a ambiência do maquinarismo digital, que os acolhe, quanto às estruturas e às linguagens lógicas, que fornecem as condições necessárias para que a arte escrita navegue fluídica e singularmente na www - World Wide Web. Contudo, através da virtualidade, aqueles renovam o processo pelo qual a Literatura expressa seu nível estético e de acento indomável, conduzindo os novos comportamentos acerca do que é artístico no universo on line. Quais sejam: o módulo criador - o artista -, o módulo criado - a obra de arte, neste caso, a literária -, e os módulos recepcionais - os leitores. Assim, clarifico nesta reflexão que a teia expande seus limites indemarcáveis para além do olhar humano, destituído de poderes divinais, no mundo digital - complexo lógico e estrutural -, e para além da consciência dos receptores, na ambiência translógica (grifo meu).

A teia em literatura, por ser objeto artístico, dinamiza o duplo, pois o ducto poético revela a malha textual, navegando na rede imaginária, que perfaz a tessitura literária, no exercício profícuo da interação, em níveis distintos; e ultrapassa as fronteiras midiáticas da aldeia global, através da rede mundial de computadores, mantendo blindada 
a sua mensagem, senão deificada e poeticamente trançada pelo artista que a criou.

O ideário entabulado na problematização, que ora apresento, sobre o texto e o hipertexto artísticos, respectivamente, e o casulo que os abriga - a internet -, somente poderia ser construído, tendo como base o abstracionismo que reúne dois universos singulares, aparentemente díspares, mas complementares na realidade dominada pela virtuosidade da linguagem digital ou pela virtualidade da linguagem extraordinária. O link que estabeleço, portanto, a partir da assertiva anterior interposta, é o elo que conectará mais do que dois universos em um território que se desterritorializa, ao crescer, esfericamente, para todos os lados e ao abrir portais infinitos - Windows -, além de um número infindável de universos dimensionáveis e não - dimensionáveis pela linguagem literária, no vértice de sua poiesis. Os tais espaços que, em verdade, aferem o adimensionalismo radicado no dito e aprofundado no não - dito da palavra tornada lógos, contemplam o inefável em Literatura pelo intangível na realidade virtual, onde a mensagem navega, atinge portos conhecidos e desconhecidos, hipertextualiza o texto em labirintos magistrais e mantém o silêncio do verbo como a energia que sustenta os corpos textuais, mobilizando a malha textual e metabolizando o movimento das margens, que avança, sem fronteiras, para topias sempre renovadas. Outrossim, é na linguagem abstrata, que permeia os possíveis universos on line, da qual se extrai a verdade cifrada a caracterizar o espaço virtual, onde a linguagem digital é a expressão concreta da www.

A temática do universo on line, abordada pela reflexão teórica, que introduzo, a fim de estabelecer as modulações espaciais das linguagens das interfaces, dos intercursos, das interações, das interlocuções e, sobretudo, dos intermezzos, constitui-se nos tópos tensionais 
no qual a verdade (da) poética é, indubitavelmente, a massa amorfa, conteudisticamente densa, que se divide em dois tomos diferenciais, mas que não são antagônicos entre si. O universo tem sua razão de ser somente a partir de sua divisão. Não há movimentos tensionais sem a fragmentação da realidade. Tanto maior a possibilidade para quebrar a vidraça, que formata a realidade, maior a capacidade de percepção doutras realidades, que não existiram a partir da fratura do eixo que sustenta o Uno, na origem sempre indivisível. O fenômeno observado em modo reverso, tendo como ponto referencial o próprio fragmento, revela que a origem não é fragmentária, e, sim, unitária. Textos também são unívocos, uníssonos e podem até ser ubíquos. Porém, textos também são divisíveis, fragmentários e tomísticos. Na divisão, a constatação inquestionável da divergência; e a Literatura, em sua indivisibilidade aparente, modula o diverso para provocar outros diversos, não - contáveis, não - quantificáveis, mas, indelevelmente, perceptíveis e reais. Este é, afirmativamente, o verdadeiro Ser da Literatura, qualquer que seja a sua modulação, qualquer que seja o ambiente na qual aquela transita. Na realidade concreta e/ou na realidade virtual, o vigor do texto, na qualidade de literário, está/estará protegido pela senha do Inefável. Não há rupturas de lacres nem tampouco violação das leis, que reconhecem aquele como um autêntico canal de emissão da mensagem em processo de (de)ciframento contínuo, atemporal e eterno da Arte. O universo on line proporciona ao usuário da rede mundial de computadores, seja o acessante, na condição de internauta, que busca o conhecimento ou o entretenimento, seja o artista, que incorpora a mídia digital para a criação e a consequente transmissão de sua obra no espaço virtual, a conscientização e a observação do ludismo, que promove a Arte, ao se manifestar na realidade dos dígitos, irrevogavelmente, sob o primado do enigma. No mundo virtual, a navegação, à qual os internautas se submetem, nada mais é do que uma 
grande metáfora para elevar a precisão do maquinarismo à força do imaginário, que, a começar pelo ato de interação com a máquina, fazse necessária a recorrência àquele, e que sem o qual, homens, deuses, obras, máquinas e, por último, poetas não sobrevivem. O mundo virtual é tracionado pela força da imaginação; e, ao navegar, o passageiro on line depara-se com mares e oceanos sem horizontes à vista. Os portos aparecem na medida em que a nau avança, segundo os propósitos do navegante, pois o universo está pronto, as ilhas estão distribuídas, as águas conduzem inumeráveis mensagens, e as naves na rede e os canais de passagem para outros universos são abertos para ampliar os limites indevassáveis da Linguagem. Poetas, viajantes, bólidos virtuais e hipertextos artísticos formam um corpo ímpar nos multiversos.

É indissociável, portanto, a natureza humana da realidade virtual, que, ao se sobrepor ao mundo digital, pode, efetivamente, concretizar o fenômeno do hipertexto poético na tela do computador, que é a primeira janela aberta (window) a aparecer diante de olhos humanos a fim de viabilizar o grande salto quântico e experienciar os diversos tópos existentes, para além do universo; ou, para ser mais objetivo, os multiversos como desdobramentos do universo. Universo, diversos e multiversos são a representação iconográfica, em escala reduzida, dos espaços desconhecidos pelo Homem em outras dimensões. Assim, é factível afirmar que tais representações são modelares na medida em que se constituem pontos de referências para o movimento do corpo textual, ao navegar, metassignificativamente, no mundo virtual, marcado pelo acento on line. Neste sentido, navegar significa estar em módulos singulares, que viajam pela rede digital, ou ter, no próprio corpo do texto e na condição de malha textual, os espaços abertos, que promovem os saltos qualitativos, através dos possíveis links que aparecerem, configurando, desse modo, em estágio avançado, a hipertextualização do complexo poético. 
Neste condicionamento superestrutural ou hiperestrutural do(s) corpo(s) textual(is) que está/estão na esfera virtual, redimensionando os limites da significação, seja no campo metonímico, e da ressignificação, seja no campo metafórico, a malha que cinde barreiras, e que, simultaneamente, apresenta os elos modulares, ao longo do tecido exposto e sobrevivente no espaço on line, realiza, no espaço virtual, o desejo coletivo da Humanidade, em tempos pós-cibernéticos. Qual seja: a abertura dos portais para acessar o Hipertexto. Neste sentido, universos, diversos e multiversos triangulam-se para desvelarem a linguagem poética. A teia, portanto, em terceira dimensão, recebe o texto que se hipertextualiza, e que, ao se redimensionar, ultrapassa outros níveis da realidade para contemplar a aparição e a existência de vários universos; todos paralelos, regidos por leis próprias e sem conflitos, que possam colocar em risco o trânsito da mensagem, neste caso, a poética. Os conflitos, se existirem, estarão localizados nas unidades que compõem a máquina propriamente dita: hardware e software, pois a linguagem literária é imune a conflitos de qualquer natureza, que impeçam a sua manifestação. A sua natureza, que se superpõe a toda estrutura organizacional, construída e/ou elaborada, curiosamente, existe para gerar conflitos e não para sofrer pulsos sistêmicos. O conflito gerado pela linguagem literária está, inequivocamente, relacionado à capacidade fundante da poiesis, ao produzir, veicular, guardar e proteger a verdade contra todos os ataques virais, que, possivelmente, possam acontecer. Neste sentido, é lícito afirmar, também, que cargas virais acometem programas e máquinas computacionais, mas a linguagem poética traz, em sua essência, o seu próprio sistema de segurança, que afere o grau de proteção, de que necessita aquela, para que a verdade do texto literário, convergindo para o espaço tensional (o conflito) seja mantida sob a égide da imutabilidade. É imperioso destacar, portanto, que a realidade virtual sofre o processo mutatis mutanti; a 
linguagem literária, ao contrário, é imutável e eterna; permanente e hologramática; multifacetada e labiríntica; em última análise, preparada para navegar livremente nos espaços dos multiversos.

A teoria dos multiversos, que hodiernamente domina a cena na física quântica, mas ainda em processo de ampla discussão e com hipóteses robustas quanto à existência daqueles, pode, afirmativamente, estar presente no espaço ilimitado da Literatura, que, a meu ver, antecede a inúmeras descobertas científicas noutros campos do saber. $\mathrm{O}$ abstracionismo da Literatura conjugado com a abstração, tão necessária para os cientistas quânticos, encontra, na linguagem poética, o ponto convergente e o acesso singular para realidades antes impensáveis, em se tratando de mundos paralelos, realidades virtuais, e, em minha proposição, nos multiversos. Neste sentido, cumpre asseverar que a condição basilar para um que um texto navegue em canais midiáticos é que a mensagem veiculada, em sua forma latente, seja marcada pela possibilidade de sua extensão significativa, ao lhe conceder o poder e o vigor necessários para atingir a Hipertextualização. No caso do texto artístico, o que está em latência ascende, extraordinariamente, para o transcendente, e a hipertextualização é, com efeito, um evento sui generis do texto poético, que, no espaço virtual, amplia o sentido da significação, alcança o patamar da metassignificação e, por fim, passa a ressignificar as realidades virtuais e reais coexistentes nos multiversos, que emergirem, através dos labirintos simbólicos, sempre crescentes em rede e na rede.

Por excelência, a Literatura, antes de ser Real, é Virtual. Por excelência, a hipertextualidade é a condição sine qua non para que o texto poético transfigure a realidade na qual emergiu como mensagem a navegar em universos em profusão. Por excelência, a poiesis lança a sua rede viva, vertical e atemporal nas realidades de apreensão de suas verdades recônditas. 
$\mathrm{Na}$ rede, a descoberta dos elos permanentes e renovados - portais enigmáticos, que conduzem mortais, divindades e poetas aos multiversos; dimensões de uma linguagem, que se confunde com a própria essência, em sua manifestação primeva; radicalmente poética; entidade suprema do imaginário, onde versos, universos, diversos e multiversos compõem um corpo atômico.

MULTIVERSES' CONCEPT INFLECTIONS IN LITERATURE: HIPERTEXTUAL LABYRINTHS

\section{ABSTRACT}

Poeticism and reflexion about hipertext in Literature and its epistemologic unrolling. Text, hypertext, literal net and contexture complex: text modulations in on line's universe and dimensional and non dimensional spaces in www. Hipertext literary variants and its modulations in language play which processes the virtual phenomenon. Real and virtual that joins the semantic literary text's chains. Signification, metasignification and resignification of literary text and hypertext ones and also on line artistic language portals opening. Introduction of mulitverses conception in Literature and renewing of the thinking limits conception of artistic literary.

KEYWORDS: Hipertext. Literal net. Resignification. Multiverses. Poeticism.

\section{BIBLIOGRAFIA}

ANGENOT, M et al. Teoria literária: problemas e perspectivas. 1. ed. Lisboa: Publicações Dom Quixote, 1995.

BARTHES, R. A câmara clara: nota sobre a fotografia. Rio de Janeiro: Nova Fronteira, 1984.

BOHR, N. Física atômica e conhecimento humano. Rio de Janeiro: Contraponto, 1995.

CORREAA, I. E. J. Fronteiras da literatura: discursos transculturais. Vol. II. Rio de Janeiro: Relume Dumará, 1999.

ECO, H. Semiótica e filosofia da linguagem. São Paulo: Ática, 1991. HEIDEGGER, M. Sobre a essência do fundamento, a determinação do ser do ente segundo Leibniz \& Hegel e os gregos. São Paulo: Livraria 
Duas Cidades, 1971.

HEISENBERG, W. A parte e o todo. Rio de Janeiro: Contraponto, 1996. LEÃO, E. C. Aprendendo a pensar. Petrópolis: Vozes, 1971. LEÃO, E. C. Aprendendo a pensar. Vol II. Petrópolis: Vozes, 1991. LEVY, P. O que é o virtual? 1. ed. São Paulo: Edições 34, 1996. RIBEIRO, J. C. S. Mário de Sá-Carneiro: o vôo da esfinge - das sombras da decadência à poética do desastre. Rio de Janeiro, 2001. Tese (Doutorado) Faculdade de Letras, Universidade Federal do Rio de Janeiro. RIBEIRO, J. C. S. Mário de Sá-Carneiro: entre o enigma e a esfinge - o corpo plasmático na poética do desastre. Rio de Janeiro, 2004. Tese (PósDoutorado) Faculdade de Letras, Universidade Federal do Rio de Janeiro. STRATHERN, P. Bohr e a teoria quântica em 90 minutos. Rio de Janeiro: Jorge Zahar Editora, 1999. 